\title{
LAS RUTAS INTERREGIONALES EN EL PERIODO FORMATIVO PARA EL NORTE DEL PERÚY EL SUR DE ECUADOR: UNA PERSPECTIVA DESDE EL SITIO INGATAMBO, VALLE DE HUANCABAMBA
}

\author{
ATSUSHIYAMAMOTO \\ UNIVERSIDAD DE SAITAMA \\ llamamototaxi@yahoo.com
}

\section{RESUMEN}

En este artículo presentaremos una hipótesis sobre las rutas interregionales en el periodo Formativo para el Norte del Perú y el Sur de Ecuador desde una perspectiva del valle de Huancabamba, prestando especial atención al sitio arqueológico Ingatambo. Esta hipótesis se basa en un análisis SIG (Sistemas Geográficos de Información) sobre «rutas de costo mínimo» y la comparación de los materiales arqueológicos. Dicho análisis dio como resultado que las rutas fueron transformándose gradualmente durante el periodo Formativo Medio debido al cambio del traslado a pie hacia el uso de camélidos, el cual se relaciona estrechamente con un cambio social en los sitios conectados por ellas. Considerando los datos obtenidos del sitio Ingatambo, se observa una relación entre la selección de rutas y el contexto social, donde se vuelve importante la estrategia social del intercambio interregional y el establecimiento de contacto con grupos en zonas aledañas.

Palabras ClaVe: Rutas de intercambio, SIG, rutas de costo mínimo, medios de transporte, Ingatambo.

\begin{abstract}
This article presents a hypothesis about the interregional exchange routes during the Formative period in northern Peru and southern Ecuador from the point of view the Huancabamba Valley, especially the archaeological site of Ingatambo. This hypothesis is based on an analysis of GIS (Geographic Information Systems), «least-cost paths», and the comparison of archaeological materials. This analysis showed that the routes transformed gradually during the Middle Formative period due to a change in the transportation means, from traveling on foot to the use of camelids, which was closely related to the social change of the sites connected by them. Considering the excavated data of Ingatambo, there is a relationship between the selection of routes and the social context where interregional exchange and the establishment of contact with groups in neighboring areas become important as a social strategy.
\end{abstract}

KEYWORDS: Exchange routes, GIS, least cost paths, transportation, Ingatambo. 


\section{INTRODUCCIÓN}

Se puede considerar que el intercambio o la relación interregional es un factor y/o impulsor muy importante que se relaciona con el cambio social y es un tema principal en la arqueología y la antropología. En el caso de los Andes, se ha discutido el intercambio interregional en diferentes circunstancias entre los sitios arqueológicos del periodo Formativo y su relación con el cambio social (Bandy 2005; Burger 1992: 220-227, 2003; Burger y Matos 2002; Guffroy 1989: 203, 2008; Hocquenghem 1991: 312314; Hocquenghem et al. 1993). Estudios previos consideran la relación interregional principalmente sobre la base de la semejanza de materiales arqueológicos obtenidos en diversas zonas ecológicas distanciadas entre sí en la costa y la sierra, así como en la selva. Sin embargo, para pensar acerca del movimiento de los materiales arqueológicos, es obviamente necesario considerar la existencia de los humanos que lo realizaron entre las distintas sociedades. Por tal motivo, en ese artículo tomaremos en cuenta las rutas interregionales para discutir las actividades y movimientos humanos, y acercarnos a la posible imagen real del intercambio interregional. Consideramos que el estudio sobre el intercambio interregional debe enfocarse no sólo en la comparación de los materiales arqueológicos, sino también en el análisis de las rutas interregionales. Vale la pena mencionar que el objetivo final del presente estudio sobre rutas no se enfoca en su identificación, sino en entender la dinámica social del periodo Formativo a través de su existencia.

\section{Antecedentes}

\subsection{RELACIONES INTERREGIONALES Y RUTAS EN EL PERIODO FORMATIVO EN LOS ANDES}

Al revisar estudios previos se puede encontrar dos perspectivas acerca de las relaciones interregionales para el periodo Formativo. Una de ellas considera la relación interregional a través de la extensión de la distribución de materiales arqueológicos semejantes, denominada «esfera de interrelación» (Burger 1984, 1992, 2008; Church 1996). Otra considera la relación interregional a través de los sitios arqueológicos como nudos en una red (Pozorski y Pozorski 1987). Ambas perspectivas deben separarse y/o usarse al mismo tiempo dependiendo del objetivo del análisis y la escala al examinar la relación interregional, dependiendo además de los modelos adoptados sobre comportamiento humano para entender las relaciones entre sitios y las características de cada relación.

En estudios recientes de las sociedades del periodo Formativo es evidente la existencia de una diversidad regional gracias a la acumulación de investigaciones arqueológicas, por lo que se necesita un análisis detallado considerando el contexto social de cada sitio o región para deliberar sobre el tema del intercambio. Sin embargo, poco se ha discutido para este periodo acerca de las rutas interregionales hasta el presente. Los estudios acerca de rutas de intercambio en los Andes se centran principalmente en periodos postformativos (Topic y Topic 1983), como es el caso del camino Inca (Hyslop 1984). Dado que es difícil encontrar los restos de las rutas con revestimiento del suelo, suponemos que para el caso del periodo Formativo se trato de un camino apisonado o sendero. Esta característica permitiría deducir sólo dos rutas para este periodo: una ruta a modo de puente cerca del sitio de Chavín de Huantar (Diessl 2004) y un sendero entre los valles de Moche y Chicama (Beck 1990).

Aunque es difícil confirmar fehacientemente las rutas para el periodo Formativo, podemos proponer algunas posibilidades a través del análisis topográfico y de SIG (Sistemas Geográficos de Información). Al contrastar dicho análisis con los materiales arqueológicos podemos plantear algunos temas de discusión sobre el intercambio y las relaciones interregionales para este periodo.

\subsection{LOS ESTUDIOS SOBRE RUTAS EN LOS ANDES}

Los estudios sobre rutas se centran en el espacio entre los sitios arqueológicos y se pueden separar en dos perspectivas. Una se refiere al rol de la ruta y la complejidad social con la que fue construida, 
tomando en cuenta elementos como la forma, tecnología, inversión laboral y planeamiento -como es el caso del estudio sobre el camino Inca-. La otra se refiere al rol de la ruta tomado en cuenta la conexión de puntos, con uno de inicio (Trombold 1990). En el presente artículo tomaremos una posición intermedia entre ambas perspectivas tomando en cuenta la conexión de puntos, el rol de la ruta y el trasfondo social en el que se dio el intercambio.

Como mencionamos anteriormente, para el caso de los Andes existen estudios de rutas interregionales para el caso del camino Inca (Hyslop 1984) pero aun no existen muchos estudios que consideren la conexión de puntos. Por ejemplo, Topic y Topic (1983) analizaron la ruta entre la costa y la sierra norte del Perú concluyendo que existiría una relación interregional. Si bien este es un importante antecedente de estudio, no se tomó en consideración la topografía y elevación de la zona, además que no es clara la conexión de los puntos que inician las rutas. Por esta razón, en este artículo haremos frente a esta problemática utilizando el análisis SIG incluyendo información como topografía y elevación, y los sitios arqueológicos -especialmente centros ceremoniales- como puntos de ruta.

Cabe resaltar que Topic y Topic consideraron sólo dos formas de traslado (i.e. a pie y con camélidos) y no distinguieron entre esos medios de transporte en el análisis de la ruta. Sin embargo, es posible asumir que el tipo de medios de transporte influyen en la ruta y viceversa. Por esta razón, efectuamos el análisis de las rutas distinguiendo entre traslado a pie y con camélidos. Tal como Renfrew (1984) menciona, es importante considerar los medios de transporte porque, dependiendo de ellos, deben existir diferencias en el contexto y trasfondo social de las sociedades que realizan el intercambio.

Hocquenghem (1993) realizó un estudio de la ruta del Spondylus (Spondylus sp.) entre el Norte del Perú y el Sur de Ecuador sobre la base de sus investigaciones en la costa extremo norte del Perú, concluyendo que el intercambio territorial se daría por una ruta relacionada a las corrientes marinas. Considerando tal estudio, es posible asumir que el intercambio de Spondylus en el periodo Formativo se dio desde la costa del Ecuador hacia la costa norte del Perú, especialmente para el caso del sitio arqueológico Cerro Ñañanique ubicado en el valle medio de Piura. Sin embargo, dada la existencia del camino Inca en esta región, se encontrarían dos rutas principales entre Ecuador y Perú.

La primera ruta, como mencionó Hocquenghem, se extendió desde la línea de costa hasta el valle medio de la costa norte peruana, pasando por el valle medio de Piura para evitar el desierto de Sechura. La otra ruta se extendió desde la sierra del Ecuador hasta la sierra del Perú, a través del valle de Huancabamba sin pasar por el valle medio de Piura (ruta serrana). Aunque Hocquenghem no consideró la ruta posterior, existen petroglifos del periodo Formativo en Ayabaca por donde podría pasar esta ruta (Polia 1995), lo cual es comparable a casos en la costa norte del Perú (Tsurumi 2008) y la costa norte de Chile (Núñez y Dillehay 1995; Sepúlveda et al. 2005) donde se observa una estrecha relación entre rutas interregionales y petroglifos.

La poca cantidad de Spondylus encontrada en Cerro Ñañanique, aun cuando se ubica cerca de un lugar de producción, parece confirmar esta hipótesis (Guffroy 1989: 193). Esto no implica que Cerro Ñañanique no tenga relación con las sociedades ecuatorianas, sino que se puede interpretar como que esta ruta no fue la ruta principal, aumentando la probabilidad de que la ruta serrana pudiese haber sido la más utilizada para el intercambio de Spondylus. Esto se podría corroborar con los materiales cerámicos recuperados que muestran una fuerte vinculación entre Cerro Ñañanique y los sitios de Loja y Catamayo en la zona sur de Ecuador (Guffroy 1989: 203, 1992, 2004, 2008). Es necesario, entonces, considerar las formas, mecanismos y estrategias para discutir el intercambio interregional.

En los últimos años se han presentado varios estudios de rutas interregionales utilizando análisis de SIG. En un estudio pionero para los Andes, Tripcevich (2007) mostró un estudio sobre la ruta de las caravanas en la sierra sur del Perú enfocado en la relación entre su obtención y consumo de obsidiana, además de mostrar el cambio social a través del tiempo como generador de diferencia social. Si bien no discute sobre la probabilidad de la ruta misma, la selección y decisión de la ruta se realizaron 
de acuerdo al contexto y estrategía social. Por lo tanto, es importante considerar que la diferencia entre las rutas depende de los materiales intercambiados y el tiempo. Este punto lo tomaremos en cuenta para nuestro análisis de SIG, especialmente en lo relacionado a rutas de costo mínimo.

Contreras (2011) presentó un estudio rutas de costo mínimo aplicando análisis SIG. Este estudio es también significativo dado que muestra tales rutas relacionadas con los sitios arqueológicos del periodo Formativo en el Perú a gran escala. Sin embargo, creemos que este tipo del análisis es mucho más eficaz cuando se efectúa dentro de áreas en menor escala, donde se pueden tomar en cuenta características como la topografía y la influencia de corrientes de agua, además que se debe pensar no solo en la relación entre grandes centros ceremoniales alejados, sino también en la existencia y relación entre sitios intermedios que permiten entender la interrelación interregional y la dinámica social referida al intercambio. Por este motivo, el presente análisis toma como área de estudio en detalle las regiones del Norte del Perú y Sur del Ecuador.

Es evidente que existen varias rutas hacia puntos cardinales desde un sitio arqueológico, por lo que el estudio de rutas necesita aclarar no sólo la existencia de intercambio entre las sociedades sino también mostrar (1) cuál fue la ruta principal, (2) cómo se dio el intercambio y (3) cómo se relacionaba la existencia y conexión de las rutas con el cambio o desarrollo social de diferentes zonas. En el presente artículo utilizamos la comparación de los materiales arqueológicos junto con el análisis de las rutas para clarificar la dinámica de intercambio interregional como los resultados de las actividades humanas que se dan en distintas regiones. Es así que este estudio no pretende identificar una ruta antigua, sino más bien pretende funcionar como una hipótesis operativa que permita discutir las sociedades del periodo Formativo a través del análisis de rutas.

\section{Las inVestigaciones del sitio Ingatambo en el Valle de Huancabamba}

El sitio arqueológico Ingatambo se encuentra en una meseta natural ubicada en la margen sur del río Huancabamba, en el extremo norte de los Andes peruanos (Yamamoto 2007, 2010, 2012; Yamamoto y Peña 2006) (Fig. 1). Es un sitio complejo, conformado por plataformas y plazas que abarcan un promedio de 17,5 hectáreas. Mediante nuestras excavaciones hemos confirmado la existencia de tres fases constructivas en la arquitectura ceremonial perteneciente al periodo Formativo (Yamamoto 2010, 2012; Yamamoto y Peña 2007, 2008). Utilizando la cronología propuesta por los estudios previos en áreas aledañas y los datos de nuestro proyecto, la relación cronológica del sitio Ingatambo se puede ordenar como se observa en cuadro (Cuadro. 1).

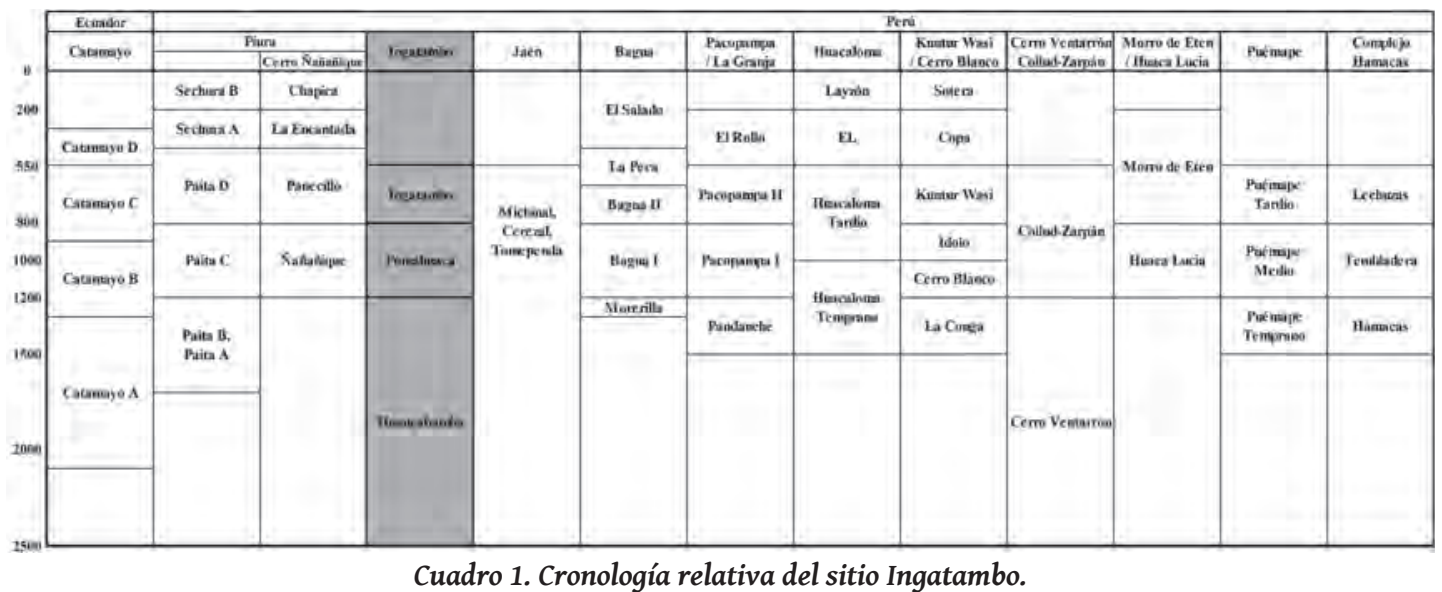

En la primera fase, denominada fase Huancabamba, se empezó a construir la arquitectura ceremonial. Es el único sitio confirmado para esta fase en el valle. La estructura fue muy singular y 


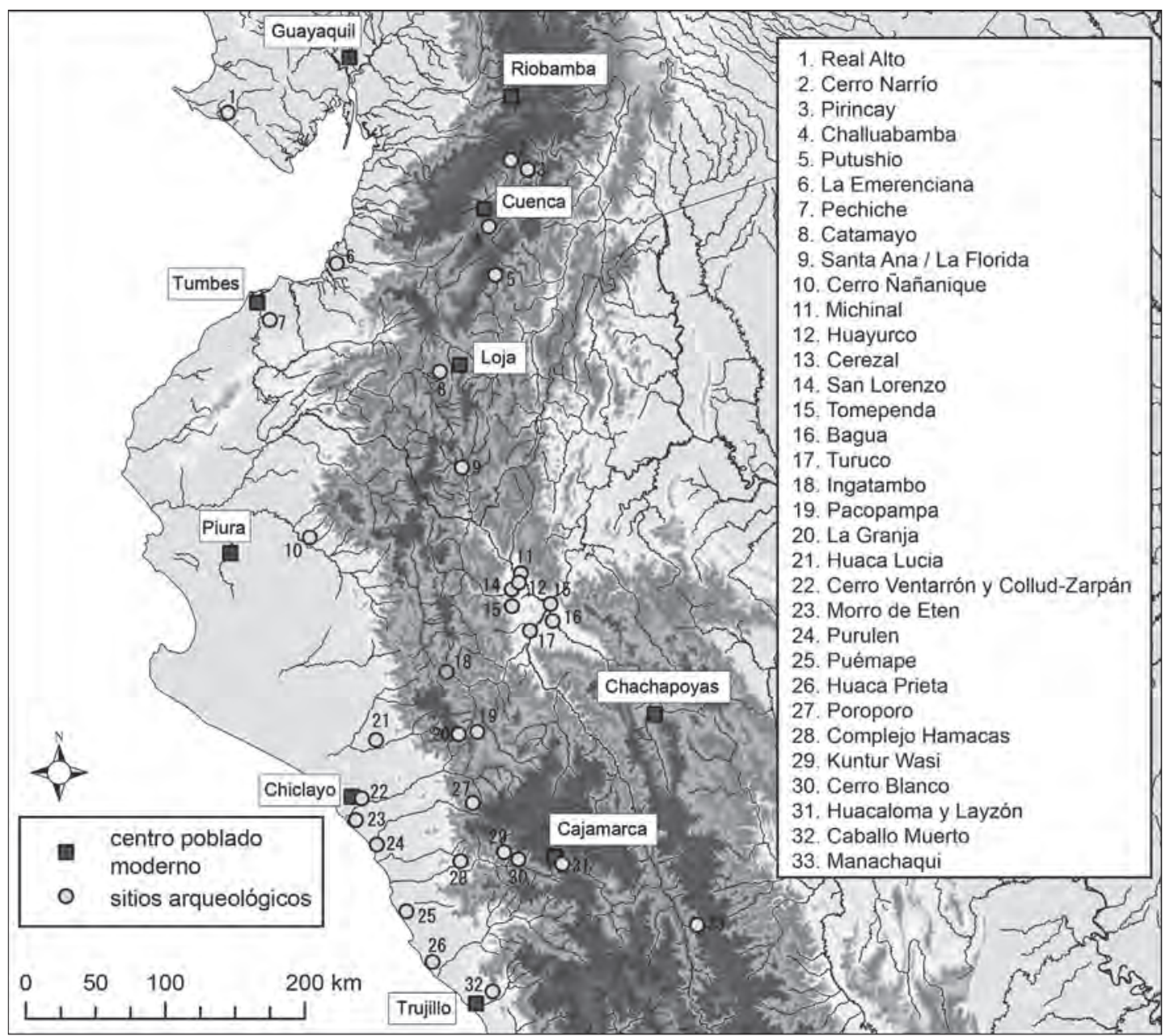

Figura 1. Ubicación del sitio Ingatambo y otros sitios relacionados al periodo Formativo.

de pequeñas dimensiones, especialmente comparada con otros sitios de la costa norte como el sitio Cerro Ventarrón (Alva 2010). Dadas sus dimensiones, esta estructura debió funcionar como un centro de integración social a pequeña escala. Es necesario mencionar que no se encontró material cerámico en esta fase -si bien ya existía en zonas cercanas del Norte del Perú como el sitio Pandanche (Kaulicke 1975; Morales 1998)-. Fuera de un espécimen malacológico marino ${ }^{1}$ no se han encontrado mayores evidencias que indiquen un contacto interregional con zonas cercanas al sitio Ingatambo, por lo que podría considerarse que existió una diferencia en cuanto al desarrollo social entre el valle de Huancabamba y sus alrededores. Es así que consideramos que se dio un proceso social propio en esta fase para el valle de Huancabamba.

Durante la segunda fase denominada Pomahuaca, se dieron varios cambios en el valle de Huancabamba. Primero, aumentó el número de sitios (incluyendo centros ceremoniales). Además, en el sitio Ingatambo se dio una renovación de la arquitectura con unos recintos muy elaborados y

1 El análisis de restos malacológicos se realizó en el laboratorio de la Universidad Nacional de Trujillo (Perú) por los biólogos Víctor Vásquez y Teresa Rosales (Vásquez y Rosales 2008, 2009). 
con un acabado de enlucido encima de la plataforma cuya forma tiene semejanza con sitios de Jaén (Miasta 1979; Olivera 1998), Bagua (Olivera 1998, 2008) y Piura (Guffroy 1994). Dado el fino acabado y la dimensión del sitio Ingatambo, este debió ser el centro principal del valle. En esta fase se encuentra mayor evidencia que nos indica la existencia de intercambio interregional, como material cerámico vinculado a sitios de zonas aledañas en Jaén (Miasta 1979; Olivera 1998), Bagua (Shady 1973, 1974, 1987, 1992, 2002; Shady y Rosas 1979, 1987) y Chota (Flores 1975; Fung 1975; Kaulicke 1975; Morales 1980, 1998; Rosas y Shady 1970). Además, hemos registrado un plato de piedra con forma de animal, el cual sería una ofrenda para la renovación de la arquitectura y que tiene semejanza con el sitio Huayurco (Rojas 1985) y otros sitios en Jaén y San Ignacio. Encontramos también materiales malacológicos, como conchas marinas. Algunos de estos materiales, entre ellos el Spondylus, se encuentran solamente en la corriente calida hasta Santa Elena en el Ecuador y otros hasta Paita en Piura, lo cual sería una evidencia de contacto con poblaciones asentadas en el litoral. En cuanto a los restos óseos, se encuentran restos de camélidos. Considerando los datos recuperados, se dio un desarrollo muy rápido en esta fase por el incremento en la interacción de los sitios (Yamamoto 2010, 2012).

Para la tercera fase denominada Ingatambo, disminuyó el número de sitios arqueológicos en el valle de Huancabamba. En el sitio Ingatambo se dio al mismo tiempo una gran renovación arquitectónica que incluyó una ceremonia de fuego y aumentó la complejidad arquitectónica en la parte superior de la plataforma con recintos muy elaborados. Es posible que se diera una concentración de la mano de obra del valle a este sitio, convirtiéndose en el centro principal en este valle.

En esta fase, en comparación con la fase anterior, se recuperaron finos materiales cerámicos de gran variedad que presentan un fuerte vínculo con fragmentos encontrados en otros sitios del Perú por su estilo, especialmente la técnica de decoración como Rojo Pintado, Post-cocción, Polícromo, Negro, Rojo y Gris Pulido (a veces Grafitado), Rojo sobre Anaranjado y formas como Olla sin cuello y Olla con cuello corto procedentes de la costa norte (Elera 1986), la costa extremo Norte (Guffroy 1989, 1992, 1994; Kaulicke 1998; Lanning 1963; Ravines 2008), la sierra norte [Flores 1975; Fung 1975; Inokuchi 1998; Morales 1980, 1998; Onuki ed. 1995; Rosas y Shady 1970; Terada and Onuki eds. 1982, 1985, 1988; Wester et al. 2000] y la selva norte (Shady 1973, 1974, 1987, 1992, 2002; Shady y Rosas 1979, 1987). Algunos de estos materiales pueden ser considerados como evidencia de transporte desde tales regiones a través del intercambio. Igualmente, se encontraron piezas a base de concha, principalmente de mar tropical, por lo que puede suponerse que el sitio Ingatambo habría también tenido una relación interregional con el Sur de Ecuador.

Se encontraron también piezas de obsidiana procedentes de Quispisisa (Ayacucho) ${ }^{2}$, abuntantes materiales malacológicos y restos óseos animales (camélidos) relacionados a la renovación arquitectónica del sitio. Considerando estas evidencias, en esta fase se habría dado una intensificación del intercambio interregional tanto con zonas cercanas como lejanas, donde el sitio Ingatambo habría funcionado de manera estratégica. La cantidad y abundancia de los materiales obtenidos, así como su semejanza con materiales cerámicos y fuentes lejanas, parecen indicar la existencia del intercambio como base para esta fase, donde estas relaciones con diversas zonas habrían sido más sólidas y fuertes que para la fase anterior (Yamamoto 2010, 2012), lo cual podría haber generado beneficios que habrían permitido el desarrollo del sitio. Sin embargo, surgen algunas preguntas con respecto a esto: ¿Cómo se efectuó el intercambio entre el sitio Ingatambo y estas zonas alejadas? ¿Se comunicaron directamente entre sitios lejanos? Para aclarar este punto, tenemos que considerar el problema de los medios de transporte.

Para la fase Huancabamba del sitio Ingatambo son muy limitados los datos relacionados al intercambio interregional. Dado que en el valle de Jequetepeque ya se supone la existencia de intercambio

2 El análisis de obsidiana se realizó con el apoyo del Dr. Richard Burger en el laboratorio de la Universidad de Missouri por el Dr. Micahel Glascock. 
entre el valle bajo y medio utilizando camélidos (Elera 1998: 239), es posible que para el caso del valle de Huancabamba este se habría dado a pie.

En la fase Pomahuaca aumentan los indicadores para la existencia del intercambio interregional y al mismo tiempo aparecen camélidos en el sitio. Si bien existe la posibilidad de que los camélidos hayan sido utilizados como alimento (Miller y Burger 1995, 2000), su aparición coincide el aumento de los materiales relacionados al intercambio. Algunos autores mencionan la existencia de una correlación entre el intercambio interregional y los camélidos, dado que éstos eran utilizados para maximizar el transporte eficientemente (Miller y Burger 1995; Uzawa 2010). En el caso de sitios contemporáneos a esta fase para el Norte del Perú, aparecen camélidos en el sitio Huaca Lucía en la costa (Shimada et al. 1982) y los sitios Pacopampa (Uzawa 2010) y Huacaloma (Shimada 1985) en la sierra.

En cuanto al momento de la introducción de camélidos para el Norte del Perú, existen algunas diferencias. En el sitio Huacaloma se da en la fase Huacaloma Temprano, contemporánea con la segunda mitad de la fase Huancabamba (Shimada 1985), mientras con el sitio Kuntur Wasi se da desde la fase Kuntur Wasi, contemporánea con la fase Ingatambo (Uzawa 2010). Además, para el sitio Cerro Ñañanique, se encuentran evidencias para la fase Ñañanique, contemporánea con la fase Pomahuaca (Guffroy 1989: 193, 1992: 102). Para el caso del Sur de Ecuador, se comenzó a utilizar los camélidos en épocas posteriores (Bruhns et al. 1990; Miller y Gill 1990).

Tomando en cuenta el medio ambiente, el valle de Huancabamba se ubica fuera de la distribución natural de los camélidos salvajes por lo que la introducción de los camélidos en el sitio Ingatambo pudo estar relacionada al transporte donde los camélidos desempeñaron un papel importante para el intercambio interregional dado el aumento de los materiales que indican la existencia del intercambio interregional, tanto para el sitio mismo como para el Norte del Perú. Es así que en la fase Pomahuaca aumentaron los materiales de diversas procedencias (como las conchas marinas) y es posible que se dieran dos tipos de medios de transporte desde dicha fase.

\section{El objetivo y METodología del ANÁlisis SIG DE LAS RUTAS}

La selección y decisión de rutas interregionales son influidas por las circunstancias sociales del intercambio. Sin embargo, otros factores (como el medio ambiente, la topografía, la corriente y el volumen de los ríos) limitan mucho la formación de una ruta en cuanto a la posibilidad de tránsito, el tiempo y costo de traslado. Los Andes se caracterizan por su diversidad en el medio ambiente y complejidad de configuración terrestre causada por las diferencias de elevación en un área compacta y pequeña. Por lo tanto son el sitio ideal para un estudio de rutas que considere la correlación entre desarrollo social y los movimientos de seres humanos y materiales en determinados tipos de medio ambiente.

Aunque todavía quedan problemas para matizar el análisis de rutas con informaciones geográficas y topográficas dada la complejidad de los datos topográficos y de elevación en los Andes, en los últimos años se ha avanzado en la digitalización y acceso de los datos geográficos, entre los cuales destacan los datos de la Misión Topográfica de Radar a bordo del Trasbordador (SRTM por sus siglas en inglés) de la NASA. Esto nos permite analizar posibilidades de rutas factibles para periodos prehispánicos incluyendo la información geográfica y topográfica. Para el caso que presentamos en este artículo, sin embargo, no nos ha sido posible integrar aún otros datos importantes -como son la vegetación y precipitaciones- por lo que nuestros resultados son sólo preliminares, y deberán ser reforzados posteriormente.

El Costo Superficial y las Rutas de Costo Mínimo son un medio para tener en cuenta el costo variable de atravesar un paisaje diverso topográficamente (Contreras 2011) y fueron tomadas en cuenta en este estudio. La metodología utilizada para el presente análisis de rutas tuvo como primer paso preparar un modelo en 3D del área del estudio sobre la base de los datos topográficos de SRTM-3 (90 
m) $)^{3}$ y los datos de la red hidráulica de los mapas digitales del Instituto Geográfico Nacional del Perú. Los programas utilizados para realizar el análisis de rutas de costo mínimo fueron ArcGIS 9.3.1 y Spatial Analyst.

El análisis de rutas de costo mínimo implica el cálculo de las rutas interactivas más eficaces entre dos puntos facultativos, y necesita establecer costos optativos y sus proporciones. En este caso, se establecieron como costos la inclinación, la influencia de los ríos y la elevación para generar un Costo Superficial.

Para el caso del costo de inclinación, se dividió la topografía en cuatro tipos por grados de inclinación $\left(0-5^{\circ}, 5-12^{\circ}, 12-19^{\circ}, 19-26^{\circ}\right)$. Dicha clasificación permite plantear posibilidades de ruta de acuerdo al paso de menores inclinaciones y evita plantear rutas de más de $26^{\circ}$, dado que estas son imposibles de transitar.

Se estableció también dos tipos de ríos, distinguiendo aquellos que tienen dificultades para ser atravesados en cualquier lugar -como es el caso del río Marañón- de otros que tienen más fácil acceso según su volumen, profundidad y caudal. Además, se toma en cuenta el grado de dificultad del traslado por vía fluvial comparado al que se realiza por vía terrestre. Se llegó a concluir entonces que la mayoría de los ríos tienen una dificultad de paso 100 veces mayor que el traslado terrestre, especialmente el río Marañón que tiene una dificultad 1000 veces mayor, por lo que se elimina la posibilidad de un traslado frecuente a través de los ríos. Si bien las características del río Marañón dificultan el paso a través de él, considerando las ubicaciones de los sitios arqueológicos y las entrevistas realizadas a los lugareños se puede sugerir que existen dos lugares por donde el río es accesible. Esta información se integró al análisis. En cuanto al costo de elevación, se dividió la topografía en curva de nivel por cada $500 \mathrm{~m}$ con motivo de evitar una ruta con altibajos intensos.

Tomando en cuenta los tres costos mencionados y su proporción se determinó dos maneras hipotéticas de traslado para el presente análisis, siendo una a pie (costo de inclinación $50 \%$ y costo de influencia del agua 50\%) y otra con camélidos (costo de inclinación 10\%, costo de influencia del agua $10 \%$ y costo de elevación $80 \%$ ). La razón del costo de elevación de $80 \%$ para el caso del traslado con camélidos se debe a que generalmente éstos se adaptan a zonas de altura donde existe alimento y agua abundante para ellos, a diferencia de las tierras de baja elevación.

Si bien puede considerarse que las condiciones observadas para nuestro estudio de rutas es muy simple, sobre todo comparando con otros estudios realizados sobre este tema (Contreras 2011; Eerkens et al. 2010; Tobler 1993), el hecho de no conocer el modo y recorrido de la ruta por la escasez de información, además de la combinación infinita de variables que pueden afectar la ruta -incluyendo aquellas que son imposibles de recuperar actualmente como vestidos, fuerza física etc.-, nos ha llevado a considerar sólo dos tipos de transporte con la metodología más simple para hacer simulación comprensible y arreglar las condiciones necesarias. Otro elemento a considerar es el hecho de que el análisis de rutas de costo mínimo no puede precisar la ruta exacta (Howey 2007), lo cual se ha tenido en cuenta en este estudio que se enfoca más bien en discutir la dinámica social del periodo Formativo a través del intercambio por rutas.

\section{LAS RUTAS PARA DOS MEDIOS DE TRANSPORTE EN EL PERIOdO FORMATIVO}

Con la metodología que hemos presentado líneas arriba, hemos analizado las rutas interregionales de costo mínimo para el Norte del Perú y el Sur de Ecuador desde la perspectiva del valle de Huancabamba, tomando especial atención al sitio Ingatambo. Los puntos de partida para las rutas son aquellos sitios arqueológicos del periodo Formativo considerados centros ceremoniales.

3 Este análisis se inició en el año 2008, por lo que no pudo utilizarse datos ASTER facilmente. El análisis se realizó con el apoyo de Mg. Yuko Ito. 
Según diversos autores (Burger 1992; Church 1996; Martin 2001; Seki 2010), los centros ceremoniales de cada lugar pueden ser considerados como centros de intercambio y es muy poco probable que no existiesen grupos de poder que lo dirigiesen y controlasen. Por tal motivo, analizamos no sólo una ruta, sino todas las posibles rutas interactivas que parten desde cada sitio. Este análisis incluyó la posibilidad de dos rutas dependiendo del medio de transporte, los cuales serían una ruta a pie y otra ruta con camélidos. Como resultado se elaboraron mapas de las rutas, separándolas según las diferentes fases del periodo Formativo y tomando especial atención para el sitio Ingatambo (Fig. 2, 3, 4 y 5).

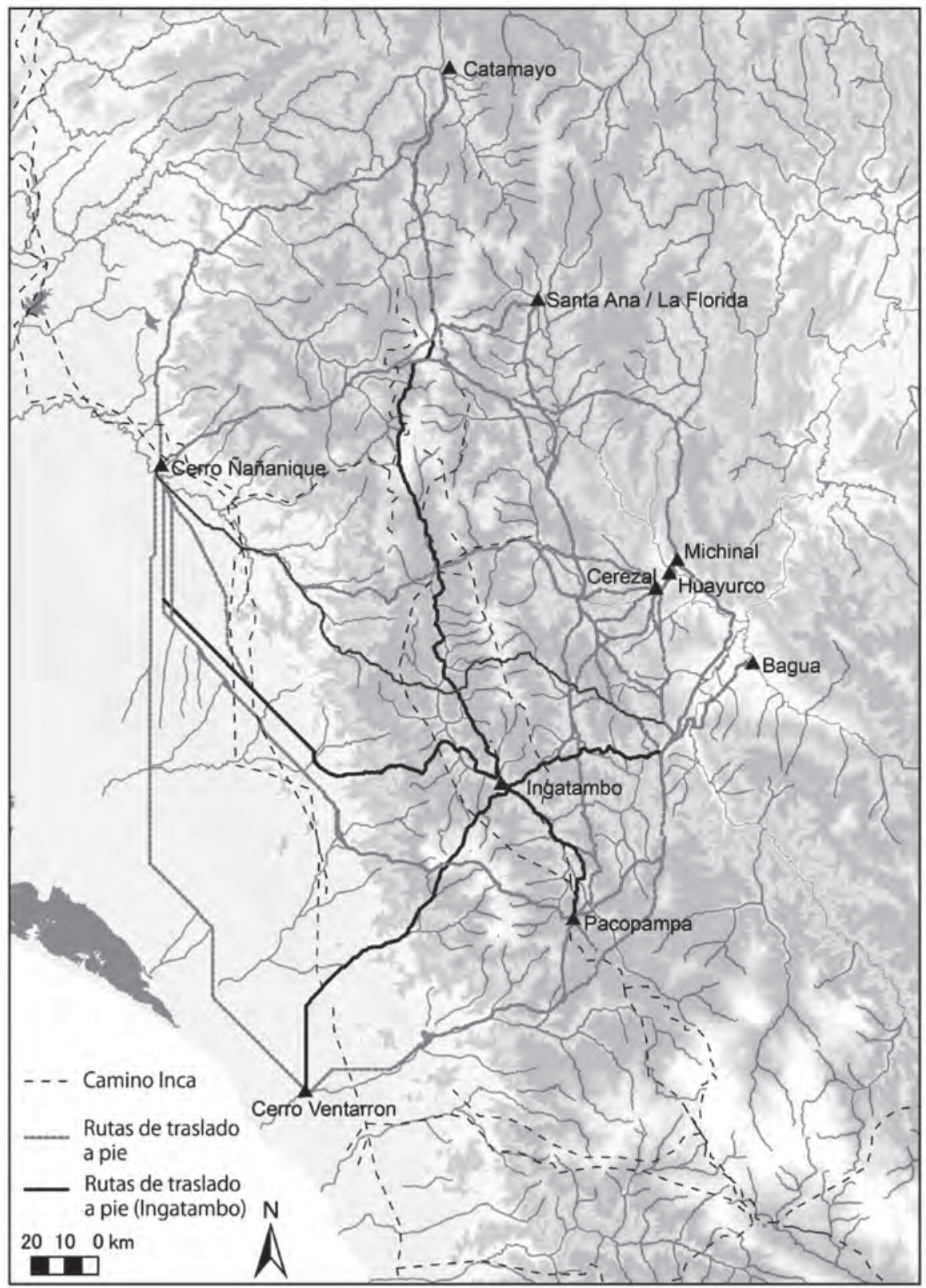

Figura 2. Resultado del análisis de las rutas interactivas de costo mínimo entre todos sitios en la primera parte de la fase Huancabamba. 


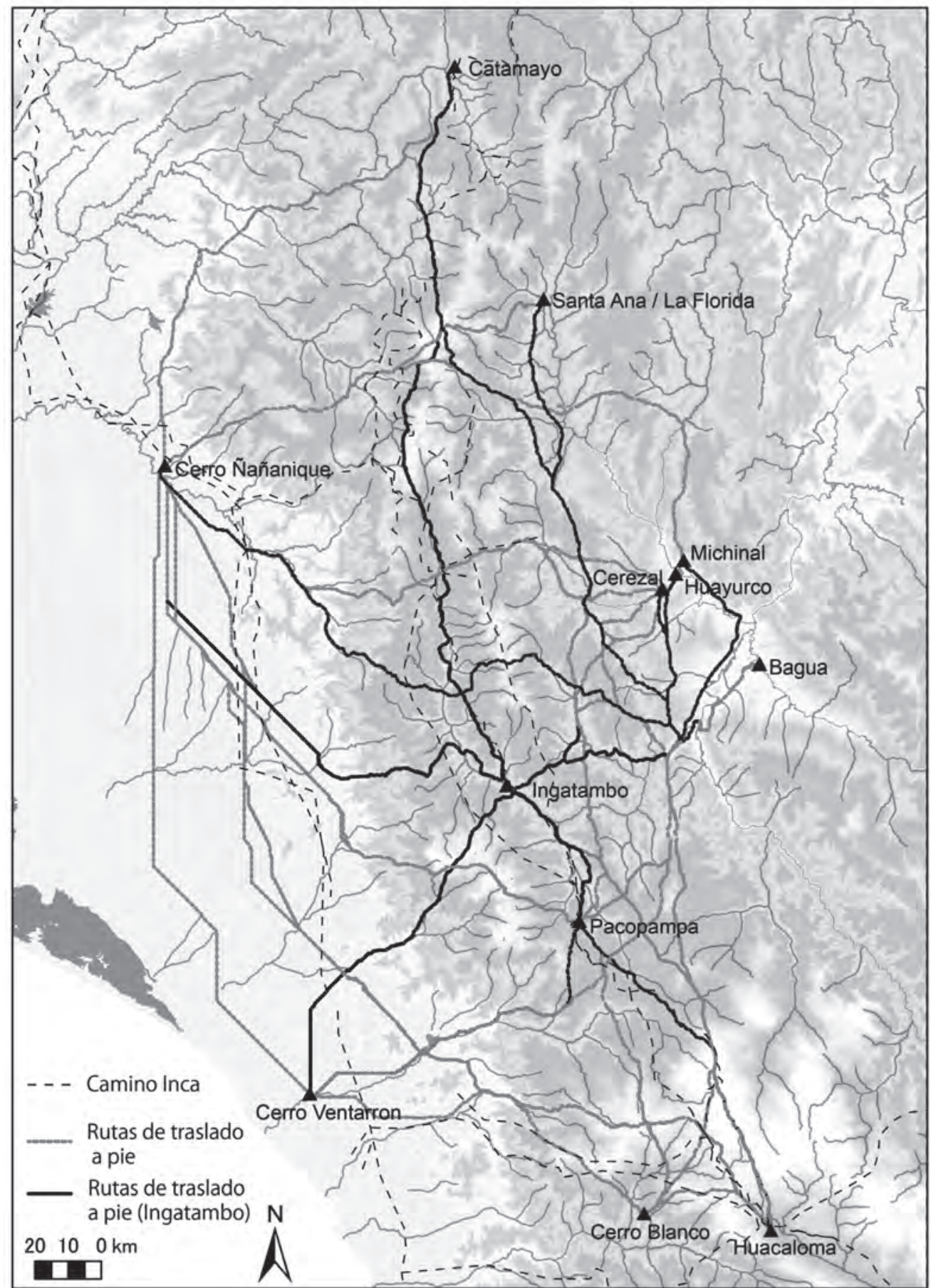

Figura 3. Resultado del análisis de las rutas interactivas de costo mínimo entre todos sitios en la segunda parte de la fase Huancabamba. 


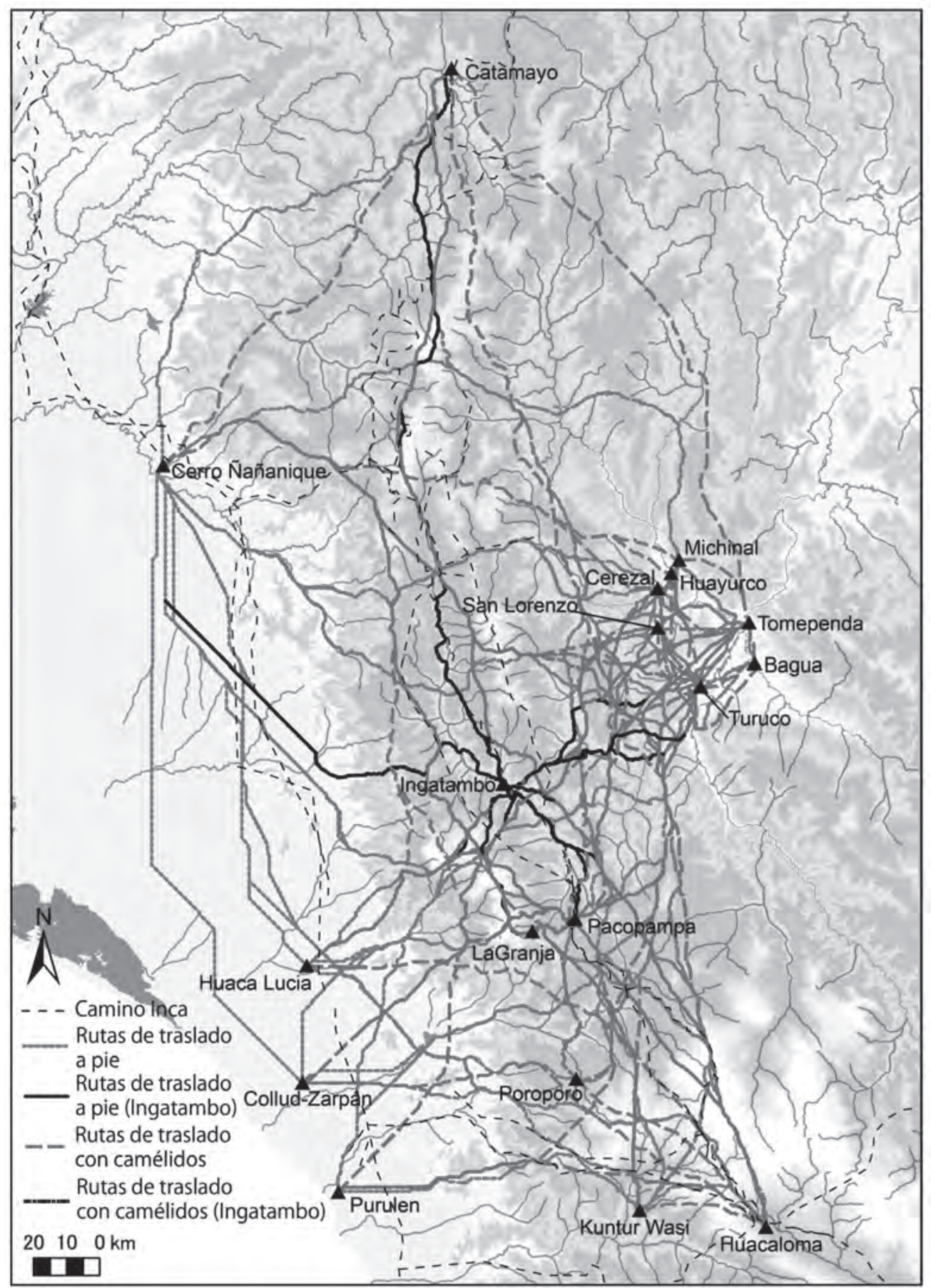

Figura 4. Resultado del análisis de las rutas interactivas de costo mínimo entre todos sitios en la fase Pomahuaca. 


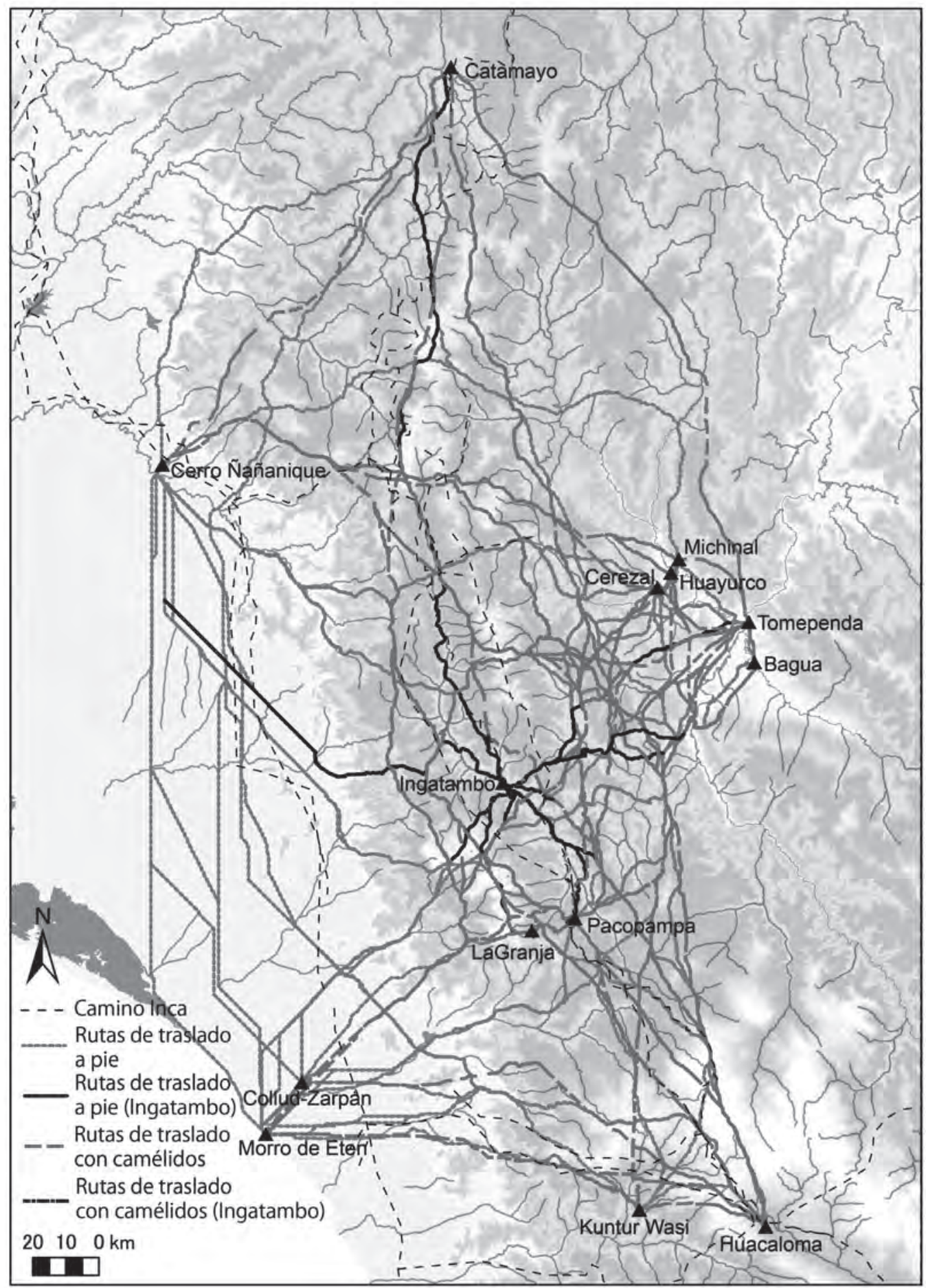

Figura 5. Resultado del análisis de las rutas interactivas de costo mínimo entre todos sitios en la fase Ingatambo. 


\section{Discusión SOBRE los DATOS OBTENIDOS}

Presentaremos a continuación una discusión sobre las diferencias a través del tiempo de las posibles rutas interregionales principales para el Norte del Perú y el Sur de Ecuador, tomando en cuenta de los resultados del análisis y comparándolo con los datos obtenidos de otras fuentes, especialmente del análisis de la cerámica.

\subsection{LA FASE HUANCABAMBA (PERIODOS FORMATIVO INICIAL Y TEMPRANO)}

Los resultados del análisis de las rutas interregionales se observan para los periodos Formativo Inicial (Fig. 2) y Formativo Temprano (Fig. 3). Aunque no ha sido posible encontrar diferencias claras entre ambos periodos durante nuestras excavaciones ${ }^{4}$, los datos fueron analizados separándolos de manera correspondiente a las fases de los sitios arqueológicos cercanos utilizados como punto de partida de las rutas.

Aparentemente, no existe una superposición de las rutas que conectan al sitio Ingatambo con otros sitios del valle de Huancabamba (Fig. 2). En otras palabras, estas rutas no tendrían mucha importancia dentro de la red interregional de esta fase por lo que se puede considerar que el sitio Ingatambo no integraría activamente la red de intercambio interregional. Esta interpretación se sustenta en que no se encontró evidencia de intercambio con las zonas cercanas para la primera parte de la fase Huancabamba durante nuestras excavaciones en el sitio. Por consiguiente, hemos identificado las rutas principales para la primera parte de la fase Huancabamba (Fig. 6) sobre la base de los datos mencionados anteriormente (especialmente a la existencia de productos de intercambio como conchas marinas) con respecto a la intensidad, existencia o inexistencia del intercambio interregional, comparando y eliminado los casos de superposición. No podemos mostrar las rutas que conectan al sitio Ingatambo con los sitios cercanos por la imposibilidad de confirmar el intercambio.

Aunque para el periodo Formativo Temprano (Fig. 3) aumentaron las rutas analizadas por el aumento de los sitios, éstas tienen la misma tendencia fundamental que para el periodo Formativo Inicial (Fig. 2), y cabe añadir que en la segunda parte de la fase Huancabamba se recuperó un objeto de conchas marinas en el sitio Ingatambo. Además, en el Norte del Perú se comenzó a utilizar cerámica con características similares a algunas zonas cercanas, con excepción del valle de Huancabamba, lo que confirmaría la existencia de un intercambio interregional.

Considerando las formas de la cerámica para el Norte del Perú y el Sur del Ecuador (Deboer 2003; Guffroy 2004; Kaulicke 1975; Lanning 1963; Shady 1973, 1974, 1987, 2002; Shady y Rosas 1979, 1987), su distribución puede ser dividida en dos zonas por la existencia o la proporción de la olla sin cuello y del cuenco de silueta compuesta. La zona norteña se vincula al sitio Bagua, y la sureña estaría ligada al sitio Pandanche.

Acerca de la cerámica decorada, se encuentra semejanza entre la fase San Juan del sitio Garbanzal con la costa sur del Ecuador (Izumi y Terada 1966), mientras que la decoración con pintura roja de la costa extremo norte del Perú nos muestra un vínculo con la sierra sur de Ecuador (Guffroy 2004, 2008; Lanning 1963). Otros materiales cerámicos muestran un fuerte vínculo entre la costa norte y la sierra norte del Perú (Kaulicke 1975; Morales 1998; Onuki ed. 1995; Terada y Onuki 1982, 1985, 1988; Seki 1998), así como también semejanza con la selva norte del Perú, como sería el caso de Bagua (Shady 1973, 1974, 1987, 2002; Shady y Rosas 1979, 1987). La semejanza de la pasta y arreglo superficial de los materiales cerámicos nos indican la existencia de intercambio en la técnica de fabricación, mientras que las características similares en la decoración, especialmente de la cerámica fina, nos indican la existencia de intercambio de elementos que incluyen una ideología relacionada con ritos o ceremonias que utilizaban los materiales cerámicos.

4 Hemos confirmado cuatro subfases dentro de la fase Huancabamba, separando las primeras dos fases para el periodo Formativo Inicial y las dos restantes para el periodo Formativo Temprano de la fase Huancabamba (Yamamoto 2012). 


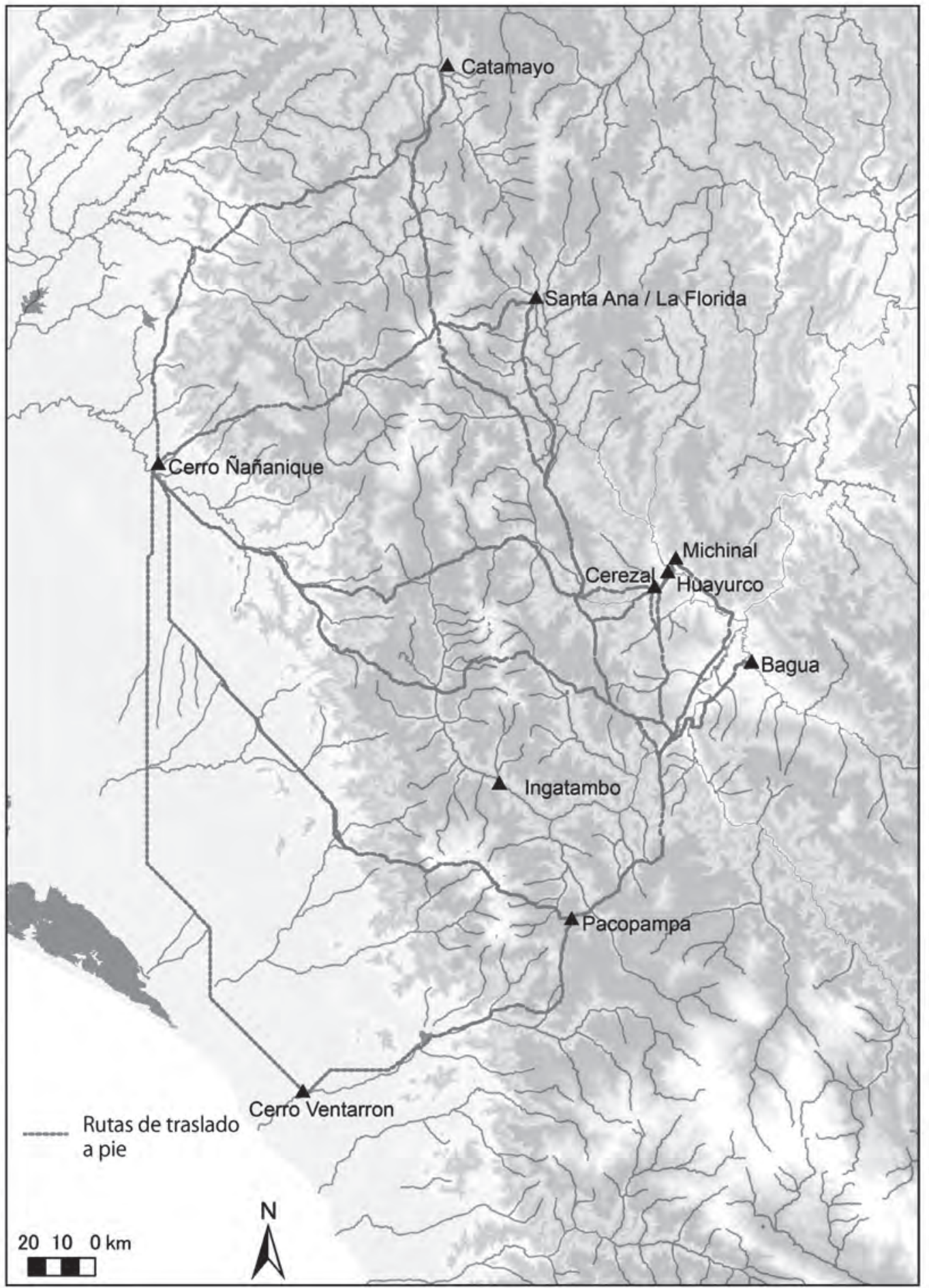

Figura 6. Rutas principales del intercambio interregional en la primera parte de la fase Huancabamba. 


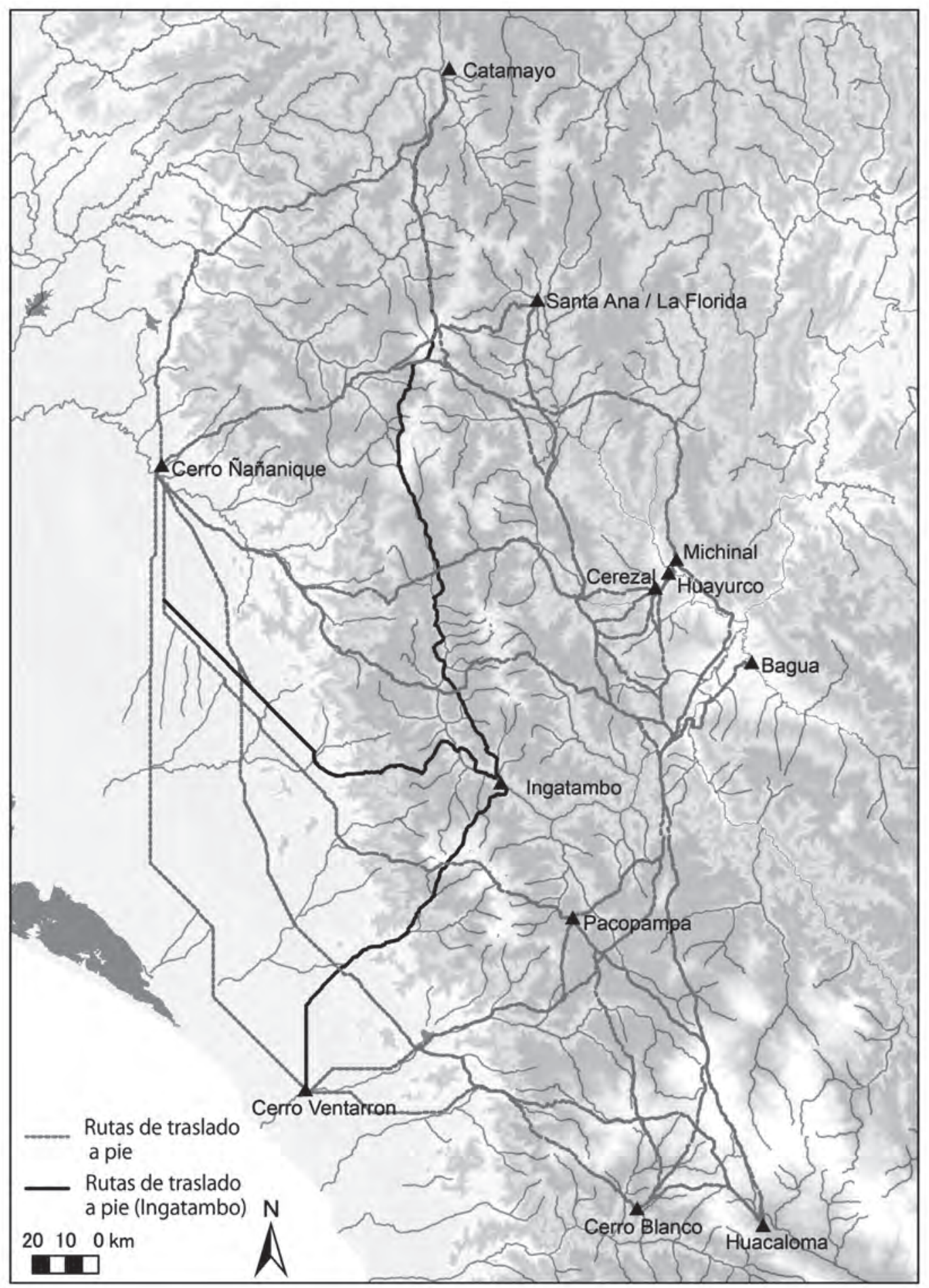


Considerando estas tendencias de la cerámica excavada, así como la existencia de conchas marinas, hemos identificado las rutas principales para la segunda parte de la fase Huancabamba (Fig. 7) de la misma manera que con la fase anterior. La diferencia entre las dos rutas planteadas (Figs. 6 y 7) resulta de considerar la existencia de ellas en relación con el sitio Ingatambo. Se puede asumir entonces que en la segunda parte de la fase Huancabamba se habría dado el intercambio entre el sitio Ingatambo y las sociedades que existieron en la costa. Cabe mencionar que para la fase Huancabamba se habría dado el traslado a pie por la inexistencia de camélidos en la zona de estudio.

Observando la semejanza y diferencia de los materiales cerámicos y la inexistencia de cerámica para la fase Huancabamba en el valle de Huancabamba, la difusión e introducción de cerámica al Perú debió ser un fenómeno muy complejo, por lo que presentaremos algunas posibles rutas que se habrían utilizado:

1. De la costa sur del Ecuador a la costa extremo norte del Perú, por el valle de Tumbes

2. De la sierra sur de Ecuador a la costa extremo norte del Perú, por los valles de Piura y Chira

3. De la sierra y la selva sur de Ecuador a la selva y la sierra norte del Perú

Sobre el tema de la difusión e introducción de la cerámica al Perú para un área amplia, debemos considerar además la existencia de rutas sobre la base de las investigaciones en Kotosh (Izumi y Terada 1972), así como una ruta entre la selva sur de Ecuador y la cuenca del Amazonas a Huanuco a través de la cuenca de Ucayali. Es así que los datos no parecen llevar a la conclusión de que se diera una ruta simple de Norte a Sur para la distribución de la cerámica.

\subsection{FASE POMAHUACA (PERIODO FORMATIVO MEDIO)}

En esta fase aumentaron los datos concretos sobre el intercambio interregional entre el sitio Ingatambo y sus alrededores con la aparición de camélidos en el Norte del Perú, cuya evidencia se encuentran en los sitios Huaca Lucia, Pacopampa, y Huacaloma. Es importante notar la coincidencia de aumento de los materiales que indican intercambio (i.e. semejanza de los materiales cerámicos y conchas marinas) con la aparición de camélidos. Por esta razón, asumimos que pudieron existir al menos dos medios de transporte y se habría dado un cambio gradual en la forma del traslado del intercambio interregional, lo cual es una interpretación que se puede dar a partir de la situación de los centros ceramoniales excavados como Pacopampa y Kuntur Wasi en la fase Ingatambo (Uzawa 2010). Además, la importancia de la forma de traslado con camélidos habría mejorado la cantidad y rendimiento del transporte, provocando el cambio de la ruta interregional para que pase por zonas de altura, donde se da un medio ambiente adecuado para los camélidos.

En esta fase existirían cuatro rutas (Fig. 4), dos de las cuales enlazan el sitio Ingatambo con sitios cercanos y otras dos que conectan sólo a los sitios arqueológicos aledaños, exceptuando a Ingatambo. La primera ruta de cada grupo sería para el traslado a pie, mientras que la segunda ruta de cada grupo sería para el traslado con camélidos. En el caso de las rutas de traslado a pie, no se dan muchas diferencias con las de la fase Huancabamba. Para las rutas de traslado con camélidos, estas pasan por el valle de Huancabamba y coinciden con otras rutas que se enlazan con el sitio Ingatambo. Se infiere entonces la incorporación de las sociedades del valle de Huancabamba (como el caso del sitio Ingatambo) en el intercambio interregional del Norte del Perú y el Sur del Ecuador. Esta tendencia es notable en las rutas que conectan la costa y la selva norte del Perú, y las de la sierra sur del Ecuador y la sierra norte del Perú.

En el intercambio entre la zona extremo norte y la sierra norte del Perú existe otra ruta al Oeste del valle de Huancambamba, aparte de la ruta mencionada como serrana. Esta ruta se ubica por el sitio Congona, donde se informó la existencia de dos monolitos con iconografía de similares características a los de Chavín de Huantar (Watanabe 2010). Sin embargo, dada la ubicación de los centros ceremoniales y la distribución de materiales cerámicos semejantes, se puede considerar que la ruta 
serrana que atraviesa el valle de Huancabamba tiene una mejor disposición para el intercambio entre la zona extremo norte y la sierra norte del Perú.

Si bien es cierto que pueden existir varias rutas para el intercambio en misma época, en este caso en particular queremos dar énfasis al uso de camélidos y cambio de rutas principales interregionales que permiten dar una interpretación del cambio social enfocado al intercambio en el valle de Huancambaba. Esta característica es especialmente importante en el caso del sitio Ingatambo, donde se empezó a utilizar la cerámica al mismo tiempo que los centros ceremoniales aumentaron sus dimensiones. También se encuentran muchos objetos hechos de conchas marinas, como el Spondylus, desde esta fase.

Las formas del intercambio de los materiales no son las mismas para cada tipo. Considerando los datos del sitio Ingatambo, la mayor proporción de vasijas toscas con forma de olla es la Olla con Cuello -una forma típica de la costa extremo norte del Perú y de Ecuador-mientras que no se puede confirmar mucho la presencia de la Olla sin Cuello, típica de la sierra sur y la costa norte del Perú (DeBoer 2003). Por la comparación del carácter arquitectónico de los centros ceremoniales, se observa la misma tendencia que en el sitio Ingatambo, la cual tiene una vinculación fuerte con la costa extremo norte (Guffroy 1994) y la selva norte del Perú (Miasta 1979; Olivera 1998). Al contrario, los materiales cerámicos finos tienen semejanzas no solo con la costa extremo norte (Guffroy 1989, 1992; Kaulicke 1998) y la selva norte (Olivera 1998; Shady 1973, 1974, 1987, 2002; Shady y Rosas 1979, 1987), sino también con la costa (Elera 1986, 1998; Shimada et al. 1982) y la sierra norte del Perú (Flores 1975; Fung 1975; Inokuchi 1998; Kaulicke 1975; Morales 1980, 1998; Onuki ed. 1995; Terada y Onuki 1982, 1985; Rosas y Shady 1970).

Desde la fase Pomahuaca en el sitio Ingatambo se recuperaron muchos objetos de conchas marinas, algunas de ellas originarias del mar tropical de Ecuador. Por eso, se puede considerar que se trajeron no solo desde la costa del Perú, sino también desde la costa de Ecuador. En este caso, sitios como Catamayo -donde se recuperaron muchas conchas de Spondylus en un depósito- (Guffroy 2004) fueron centros de intercambio. Ingatambo es otro sitio que podría ser considerado en esta categoría, dado que en él se han encontrado objetos de conchas marinas (incluyendo Spondylus) en proceso de elaboración, a diferencia de sitios como Cerro Ñañañique, donde no se encontraron conchas de Spondylus.

Sin embargo, comparando las características de la cerámica, no se encuentran muchas semejanzas directas más allá de la coincidencia entre la mayor proporción de cerámica tosca con forma de olla entre Ingatambo y sitios como Catamayo, al Sur de Ecuador. Más aún, los materiales cerámicos de Catamayo tienen mayor semejanza con los de los sitios arqueológicos en la costa extremo norte del Perú (Guffroy 1992, 2004, 2008).

La ausencia de centros ceremoniales en la costa extremo norte (Ravines 2008) y la carencia de una posible ruta marítima por la costa (Hocquenghem 1993), dada la la presencia de hallazgos en Catamayo y la ausencia de talleres en Cerro Nañanique, nos hace suponer que el transporte de conchas marinas desde Ecuador a Perú se habría realizado a través de la ruta serrana mencionada. Es posible entonces que, en las rutas que conectan la parte sur del Ecuador y el valle de Huancabamba, el sitio Ingatambo pudo funcionar como un punto importante del transporte de conchas, como nos indicó el aumento de conchas marinas tropicales desde esta fase.

Continuando con la misma metodología para fases anteriores hemos identificado las rutas principales de la fase Pomahuaca (Fig. 8). A diferencia de las rutas de la fase Huancabamba, esta tendría al traslado con camélidos como su método principal (o en proceso de serlo). Al iniciarse el transporte con camélidos, aquellas rutas que se enlazaban con Ingatambo pudieron conectarse con sitios cercanos y elevar su nivel de rendimiento. El cambio social de este sitio se relacionaría con el cambio en las rutas interregionales según los contextos sociales en zonas aledañas. De esta manera, el sitio Ingatambo aprovecharía su ubicación geográfica, concentrando su esfuerzo en el intercambio interregional a modo de estrategia social. 


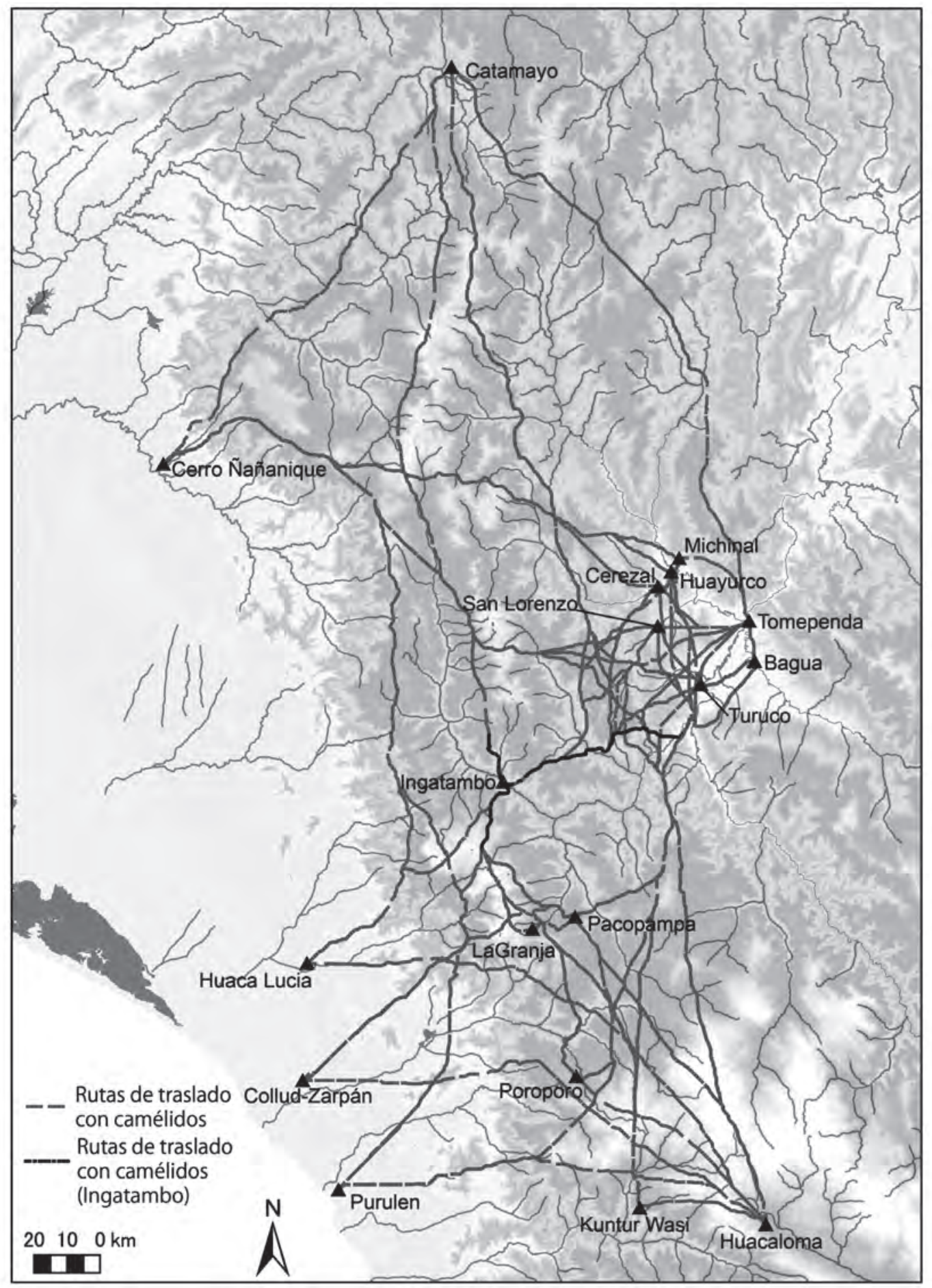

Figura 8. Rutas principales del intercambio interregional en la fase Pomahuaca. 


\subsection{LA FASE INGATAMBO (PERIODO FORMATIVO TARDÍO)}

Los resultados del análisis de las rutas interregionales (Fig. 5) aportan que en esta fase disminuyeron el número de centros ceremoniales en la costa (Onuki 1993). Sin embargo no se dio un cambio fuerte en cuanto a las rutas al compararlas con aquellas de la fase Pomahuaca.

En el sitio Ingatambo aumentaron las evidencias de intercambio interregional, la cantidad y variedad de material exótico -como conchas marinas y obsidiana de Quispisisa- relacionado a la renovación arquitectónica del sitio. En el caso de los materiales cerámicos, también aumentó su cantidad y variedad, lo que indicaría una interrelación con zonas cercanas dadas su forma, técnica y decoración (Yamamoto 2012). Aparte de estos materiales, en el museo del pueblo de Pomahuaca existen dos entierros con objetos de oro excavados clandestinamente que salieron de un recinto del sitio Ingatambo, y hemos confirmado que estos objetos pertenecen a esta fase mediante la observación de la estratigrafía en nuestras excavaciones. Entierros de este tipo se concentran en el Norte del Perú, como los casos en los sitios de Chongoyape (Lothrop 1941), Morro de Etén, Cayaltí, Zarpán (Elera 1986) y Cerro Corbacho (Alva 1992) para la costa norte; Kuntur Wasi (Onuki ed. 1985), La Granja (Wester et al. 2000) y Pacopampa (Seki 2010) para la sierra norte; Loma Macanche para la costa extremo norte (Kaulicke 1998); y Tomependa para la selva norte (Olivera 1998). Aunque no se ha confirmado la posición cronológica (excepto para el caso de los sitios Kuntur Wasi y Pacopampa) estos entierros mencionados deberían pertenecer a esta fase por la comparación de sus estilos. Sin embargo, la mayor diferencia es que para estos sitios, los entierros se dieron al inicio del periodo Formativo Tardío en el proceso de la renovación arquitectónica del centro ceremonial, mientras que para el sitio Ingatambo el entierro se dio al inicio de la subfase 2 de la fase Ingatambo en el recinto que se ubica en la parte este de la plataforma, en un tiempo un poco posterior.

Además para los casos de los sitios Kuntur Wasi y Pacopampa se sugiere una relación con la costa norte por los análisis de la cerámica y material óseo enterrados (Inokuchi 1998; Onuki ed. 1995; Seki 2010), tendencia que también existe para el sitio Ingatambo donde inclusive se dio un aumento en la cantidad de cerámica fina (Gris Fino o estilo Raku y Rojo sobre Anaranjado) que habría sido trasladada desde la costa y la sierra norte del Perú. Sin embargo, seguidamente se encontró cerámica con pintura postcocción, la cual tiende a disminuir en la sierra norte para esta fase (Flores 1975; Fung 1975; Inokuchi 1998; Morales 1980; Onuki ed. 1995; Terada y Onuki 1982, 1985). Cerámica similar se encuentra en la selva norte (Miasta 1979; Olivera 1998; Shady 1973, 1974, 1987, 2002; Shady y Rosas 1979, 1987) y la costa extremo norte del Perú (Guffroy 1989, 1992, 2008; Kaulicke 1998), por lo que se puede inferir que el sitio Ingatambo tendría una fuerte relación con las zonas mencionadas. Para corroborar esta interpretación se puede mencionar que la proporción de cerámica tosca con forma de olla es la misma de la fase Pomahuaca.

Estos datos nos indican que el sitio Ingatambo mantuvo el intercambio con la selva norte y la costa extremo norte tanto en la fase Ingatambo como la fase Pomahuaca, al mismo tiempo otorgó importancia a su relación con la costa y la sierra norte. Esta interpretación sugiere que el carácter arquitectónico del centro ceremonial del sitio Ingatambo tiene semejanza con sitios de la costa y sierra norte desde esta fase. Es posible que esta alteración del intercambio interregional fuese resultado de la alteración de la estrategia social del Ingatambo. En el caso de la sierra sur de Ecuador para esta fase, se encontró un objeto de oro en el sitio Putushio (Temme 2002) y se recuperaron fragmentos cerámicos que tienen semejanza con los sitios del Perú en los sitios de Catamayo (Guffroy 2004). Sin embargo, existe cierta diferencia en la situación social entre Perú y Ecuador como se refleja inexistencia de un centro ceremonial monumental (Burger 2003).

En cuanto a las rutas de la fase Ingatambo (Fig. 9), no existe gran diferencia con las rutas de la fase Pomahuaca, la cual sí se observa para los materiales provenientes de la fase Ingatambo y la fase anterior. Por tal motivo, consideramos que se debió dar un cambio del carácter en el intercambio interregional en esta fase. 


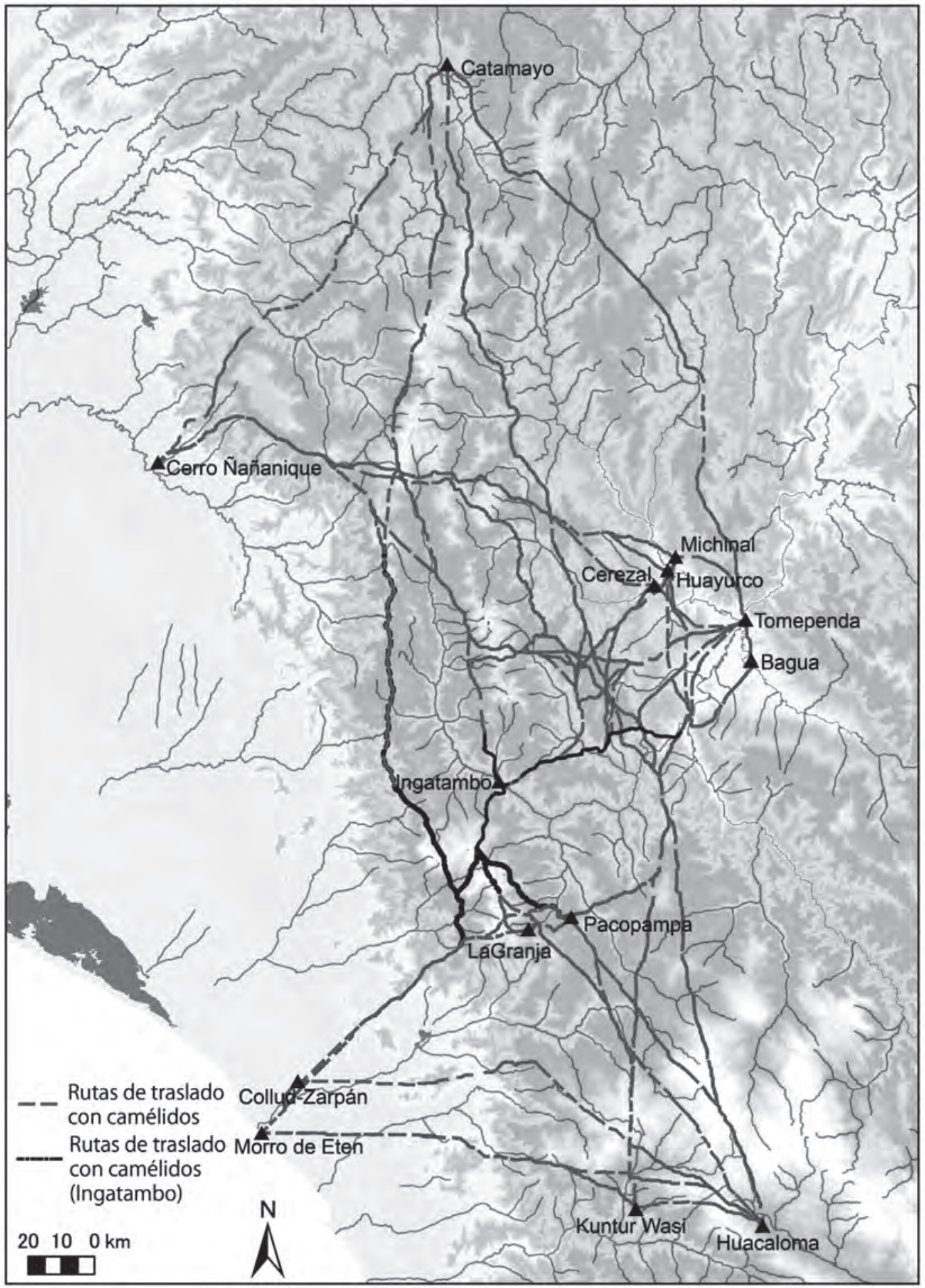

Figura 9. Rutas principales del intercambio interregional en la fase Ingatambo. 


\section{COMENTARIOS FINALES}

Para profundizar el análisis de las rutas es necesario tomar en cuenta la información geográfica y topográfica agregando atributos como la vegetación y precipitaciones, así como los materiales recuperados hasta el presente. Como vemos, aún no disponemos de datos suficientes para avanzar el estudio del intercambio o interrelación interregional, por lo que esperamos avanzar a futuro en este aspecto con excavaciones y prospecciones arqueológicas en el área del estudio para consolidar la cronología y aclarar la circunstancia social prehispánica de la zona como relación entre intercambio o interrelación y dinámica social. Además, es importante considerar la posible existencia de ciertas rutas entre sitios arqueológicos que no tengan relación con centros ceremoniales, así como realizar una discusión más profunda sobre la introducción y domesticación de camélidos para el periodo Formativo Medio del Norte del Perú.

Aún con la carencia de estos datos para el presente artículo, creemos que éste puede ser considerado como una visión novedosa que puede ayudar a contribuir un poco más a la comprensión del intercambio interregional para el periodo Formativo para esta área, por lo que esperamos a futuro poder complementar nuestros resultados con la información faltante.

\section{Agradecimientos}

El autor de este artículo sea expresar su más profundo agradecimiento a la Misión Arqueológica Japonesa, por su gran apoyo e interés. Las investigaciones de este artículo fueron financiados por los subsidios de la Sociedad Japonesa para la Promoción de la Ciencia, la Misión Arqueológica Japonesa (dirigida por los doctores Yasutake Kato y Yuji Seki) y la Universidad de Postgrado para Estudios Avanzados. Los análisis de este artículo fueron posibles gracias al apoyo del Dr. Kinya Inokuchi como la parte de los proyectos de la Universidad de Saitama para la Misión.

También quisiera agradecer al Dr. Eisei Tsurumi por sus comentarios importantes sobre este estudio, al Mg. Yuko Ito por su gran apoyo en las operaciones de SIG, y al Mg. Daniel Saucedo-Segami por su gran apoyo en la organización de las ideas del presente texto. De igual manera, quisiera agradecer a los participantes del proyecto, José Peña, Carlos Morales, Yuta Kaneko, Lúrica Hayakawa, Marina Ramírez, Jeny Ochoa, Humberto Levice, Ana Carito, Kira Dioses, Kyohei Inoue, y en manera especial a Roy Gutiérrez. Por último quisiera agradecer sinceramente a los amigos de Pomahuaca y Jaén por su amabilidad y generosidad desde el inicio de nuestro proyecto.

\section{BiBLIOGRAFÍA}

ALVA MENESES, Ignacio

2010 «Los complejos de Cerro Ventarrón y Collud-Zarpán: del Precerámico al Formativo en el valle de Lambayeque». Boletín de Arqueología PUCP 12: 97-118.

ALVA, Walter

1992 «Orfebreria del Formativo». En: J.A. Lavalle (ed.) Oro del Antiguo Perú, pp. 17-116. Lima: BCP.

BANDY, Matthew S.

2005 «Trade and social power in the southern Titicaca Basin Formative». En: K.J. Vaughn, D. Ogburn y C.A. Conlee (eds.) Foundations of Power in the Prehispanic Andes, Archaeological Papers of the American Anthropological Association, Number 14, pp. 91-111. American Anthropological Association.

BECK, Colleen M.

1990 «Cross-cutting relationships: The relative dating of ancient roads on the north coast of Peru».

En: C.D. Trombold (ed.) Ancinet Road Networks and Settlement Hierarchies in the New World, pp. 66-79, Cambridge: Cambridge University Press. 
BRUHNS, Karen O., James H. BURTON y George R. MILLER

1990 «Excavations at Pirincay in the Paute valley of southern Ecuador». Antiquity 64: 221-233.

BURGER, Richard L.

1984 «Archaeological areas and prehistoric frontiers: The case of Formative Peru and Ecuador». En: D.L. Browman, R.L. Burger y M.A. Rivera (eds.) Social and Economics Organization in the Prehispanic Andes, pp.33-71. BAR International Series 194. Oxford: British Archaeological Reports.

1992 Chavin and the Origins of Andean Civilization. Londres: Thames and Hudson.

2003 «Conclusions: Cultures of the ecuadorian Formative in their Andean context». En:J. Scott Raymond y R.L. Burger (eds.) Archaeology of Formative Ecuador, pp.456-486. Washington, D.C.: Dumbarton Oaks Research Library and Collection.

2008 «Chavín de Huántar and its sphere of influence». En: H. Silverman y W.H. Isbell (eds.) Handbook of South American Archaeology, pp. 681-703. Springer.

BURGER, Richard L. y Ramiro MATOS MENDIETA

2002 «Atalla: A center on the periphery of the Chavin horizon». Latin American Antiquity 13(2): 153-177.

CHURCH, Warren B.

1996 Prehistoric Cultural Development and Interregional Interaction in the Tropical Montane Forests of Peru. Ph.D. Dissertation, Yale University.

CONTRERAS, Daniel A.

2011 «How far to Conchucos? A GIS approach to assessing the implications of exotic materials at Chavín de Huántar». World Archaeology 43(3): 380-397 .

DEBOER, Warren R.

2003 «Ceramic assemblage variability in the Formative of Ecuador and Peru». J. Scott Raymond y R.L. Burger (eds.) Archaeology of Formative Ecuador, pp.289-336. Washington, D.C.: Dumbarton Oaks Research Library and Collection.

DIESSL, Wilhelm G.

2004 Huntar, San Marcos, Chavin: Sitios arqueologicos en la sierra de Ancash. Lima: Instituto Cultural RVNA.

EERKENS, Jelmer W., Kevin J. VAUGHN, Moises LINARES-GRADOS, Christina A. CONLEE, Katharina SCHREIBER, Michael D. GLASCOCK, Nicholas TRIPCEVICH

2010 «Spatio-temporal patterns in obsidian consumption in the southern Nasca region, Peru». Journal of Archaeological Science 37: 825-832.

ELERA, Carlos G.

1986 Investigaciones sobre patrones funerarios en el sitio Formativo del Morro de Eten, valle de Lambayeque, costa Norte del Peru. Memoria de Bachiller. PUCP.

1998 The Puémape site and the Cupisnique culture: A case study on the origins and the development of complexsociety in the central Andes, Perú. Ph.D. Dissertation. University of Calgary.

FLORES ESPINOZA, Isabel

1975 Excavaciones en El Mirador, Pacopampa. Lima: Seminario de Historia Rural Andina, UNMSM.

FUNG PINEDA, Rosa

1975 «Excavaciones en Pacopampa, Cajamarca». Revista del Museo Nacional 41: 129-207.

GUFFROY, Jean

1989 «Un centro ceremonial Formativo en el Alto Piura». Bulletin de Institut Français Etudes Andines 18 (2): 161-207.

1992 «Las tradiciones culturales Formativas en el Alto Piura». En: D. Bonavia (ed.) Estudios Arqueología Peruana, pp. 99-122. Lima: Fomciencias.

1994 Cerro Ñañanique: Un Établissement Monumental de la Période Formative, En Limite de Désert (Haut Piura, Pérou). París: Orstom Éditions.

2004 Catamayo Precolombino: Investigaciones Arqueológicas en la Provincia de Loja (Ecuador). París: IRD Éditions. 
2008 «Cultural boundaries and crossings: Ecuador and Peru». En: H. Silverman y W. Isabell (eds.) Handbook of South American Archaeology, pp. 889-902. Springer.

HOUCQUENGHEM, Anne-Marie

1991 «Frontera entre 'áreas culturales' nor y centroandinas en los valles y la costa del extremo norte peruano». Bulletin de Institut Français Etudes Andines 20(2): 309-348.

1993 «Rutas de entrada del Mullu en el extremo norte del Perú». Bulletin de Institut Français Etudes Andines 22 (3): 701-719.

HOCQUENGHEM, Anne-Marie, Jaime IDROVO, Peter KAULICKE, Dominique GOMIS

1993 «Bases del intercambio entre las sociedades norperuanas y surecuatorianas: Unas zona de transición entre 1500 a.C. y 600 d.C.» Bulletin de Institut Français Etudes Andines 22(2): 443-466.

HOWEY, Meghan C.L.

2007 «Using multi-criteria cost surface analysis to explore past regional landscapes: A case study of ritual activity and social interaction in Michigan, AD 1200-1600». Journal of Archaeological Science 34-11: 1830-1846.

HYSLOP, John

1984 Inka Road System. Academic Press.

INOKUCHI, Kinya

1998 «La cerámica de Kuntur Wasi y el problema Chavín». Boletín de Arqueología PUCP 2: 161-180.

IZUMI, Seiichi y Kazuo TERADA

1966 Andes 3: Excavtions at Pechiche and Garbanzal, Tumbes Valley, Peru, 1960. Kadokawa Publishing.

1972 Andes 4: Excavations at Kotosh, Peru, 1963 and 1966. University of Tokyo Press.

KAULICKE, Peter

1975 Pandanche: Un Caso del Formativo en los Andes de Cajamarca. Lima: Seminario de Historia Rural Andina, UNMSM.

1998 «El periodo Formativo de Piura». Boletín de Arqueología PUCP 2: 19-36.

LANNING, Edward P.

1963 "A ceramic sequence for the Piura and Chira coast, north Peru». University of California Publications in American Archaeology and Ethnology 46(2): 135-284.

LOTHROP, Samuel K.

1941 «Gold ornament of Chavin style from Chongoyape, Peru». American Antiquity 3: 250-262.

MARTIN, Alexander J.

2001 The Dynamics of Pre-Columbian Spondylus Trade Across The South American Central Pacific Coast. A Thesis Submitted to the Faculty of The Dorothy F. Schmidt College of Arts and Letters in Partial Fulfillment of the Requirement for the Degree of Master of Arts. Florida Atlantic University, Boca Raton.

MIASTA GUTIÉRREZ, Jaime

1979 El Alto Amazonas, Arqueología de Jaén y San Ignacio, Perú. Lima: Seminario de Historia Rural Andina, UNMSM.

MILLER, George R. y Anne L. GILL

1990 «Zooarchaeology at Pirincay, a Formative period site in highland Ecuador». Journal of Field Archaeology 17(1):49 -68.

MILLER, George R. y Richard L. BURGER

1995 «Our father the Cayman, our dinner the Llama: Animal utilization at Chavin de Huantar, Peru». American Antiquity 60(3), 421-458.

2000 «Chárki at Chavín: Ethnographic models and archaeological data». American Antiquity 65(3): 573576.

MORALES, Daniel

1980 El Díos Felino en Pacopampa. Lima: Seminario de Historia Rural Andina, UNMSM. 
1998 «Investigaciones arqueológicas en Pacopampa, departamento de Cajamrca». Boletín de Arqueología PUCP 2 : 113-126.

NÚÑEZ, Lautaro A. y Tom D. DILLEHAY

1995 Movilidad giratoria, armonía social y desarrollo en los Andesmeridionales: Patrones de tráfico e interacción económica: ensayo. Segunda edición, Universidad Católica del Norte.

OLIVERA, Quirino

1998 «Evidencias arqueológicas del periodo Formativo en la cuenca baja del río Utcubamba y Chinchipe». Boletín de Arqueología PUCP 2: 105-112.

2008 «Manifestaciones arqueológicas tempranas en el Alto Amazonas». Amazonía Peruana 31: 303-322.

ONUKI, Yoshio

1993 Las actividados ceremoniales tempranas en la cuenca del Alto Huallaga y algunos problemas generales. En: L. Millones y Y. Onuki (eds.) El Mundo Ceremonial Andino (Ethnological Studies 37), pp. 69-96. Osaka: Natinal Museum of Ethnology.

ONUKI, Yoshio (ed.)

1995 Kuntur Wasi y Cerro Blanco, dos sitios del Formativo en el Norte del Perú. Hokusen-sha.

POLIA MECONI, Mario

1995 Los Guayacundos Ayahuacas: Una Arqueología Desconocida. Lima: PCUP y Concejo Municipal de Ayabaca.

POZORSKI, Shelia y Thomas POZORSKI

1987 Early Settlement and Subsistence in the Casma Valley, Peru. University of Iowa Press.

RAVINES, Rogger

2008 «A cerca de la arqueología de Piura». Boletin de Lima XXX 154: 31-150.

RENFREW, Coloin

1984 «Trade as action at a distance». En: R. Colin (ed.) Approach to Social Archaeology, pp. 86-134. Cambridge: Cambridge University Press.

ROJAS PONCE, Pedro.

1985 «La huaca Huayurco, Jaén». En: R. Ravines (ed.) Historia de Cajamarca I: Arqueología, pp.181-186. Cajamarca: INC.

ROSAS, Hermilio y Ruth SHADY

1970 Pacopampa: Un Centro Formativo en la Sierra, Nor-Peruana. Lima: Seminario de Historia Rural Andina, UNMSM.

SEKI, Yuji

1998 «El periodo Formativo en el valle de Cajamarca». Boletín de Arqueología PUCP 2: 147-160.

2010 «Generation of power in the Formative period society». En: Y. Onuki, Y. Kato y Y. Seki (eds) Ancient Andes: The civilization that originated from the temples, pp.153-202. Asahi press. [en japonés].

SEPÚLVEDA, Marcela, Álvaro ROMERO GUEVARA y Luis BRIONES

2005 «Tráfico de caravans, Arte rupestre y ritualidad en la quebrada de Suca (Extremo Norte de Chile)». Chugara, Revista de Antropología Chilena 37-2: 225-243.

SHADY, Ruth

1973 La Arqueología de la Cuenca Inferior del Utcubamba. Ph.D. Dissertation. UNMSM.

1974 «Investigaciones arqueológicas en la cuenca del Utcubamba, Amazonas». Artículo reproducido de las Actas del XLI Congreso Internacional de Americanistas, 3: 579-589. México.

1987 «Tradición y cambio en las sociedades Formativas de Bagua, Amazonias, Perú». Revista Andina 5: 457-487.

1992 «Sociedades del nororiente Peruano durante el Formativo». Pachacamac Revista de Investigaciones del Museo de la Nación 1(1): 21-47.

2002 «Sociedades Formativas de Bagua-Jaén y sus relaciones Andinas y Amazónicas». En: P. Ledergerber (ed.) Formativo Sudamericano, Una Revaluación, pp. 201-211, Quito: Abya-Yala. 
SHADY, Ruth y Hermilio ROSAS

1979 «El complejo Bagua y el sistema de establecimientos durante el Formativo en la sierra norte del Perú». Ñawpa Pacha 17: 109-154.

1987 «Tradición y cambio en las sociedades Formativas de Bagua, Amazonas, Perú». Revista Andina 2: 457-487.

SHIMADA, Izumi, Carlos ELERA G. y Melody J. SHIMADA

1982 «Excavaciones efectuadas en el centro ceremonial de Huaca Lucia-Cholope del Horizonte Temprano, Batan Grande, costa de Perú: 1979-81». Arqueológicas 19: 109-210.

SHIMADA, Melody J.

1985 «Continuities and changes in patterns of faunal resource utilization: Formative through Cajamarca periods». En: K. Terada and Y. Onuki (eds) The Formative Period in the Cajamarca Basin, Peru: Excavations at Huacaloma and Layzón, 1982, pp. 289-310. University of Tokyo Press.

TEMME W, Mathilde

2002 «El Formativo en Putushío: Sierra sur del Ecuador». En: P. Ledergerber (ed.) Formativo Sudamericano, Una Revaluación, pp. 124-138. Quito: Abya-Yala.

TERADA, Kazuo y Yoshio ONUKI (eds.)

1982 Excavations at Huacaloma in the Cajamarca Valley, Peru, 1979. University of Tokyo Press.

1985 The Formative Period in the Cajamarca Basin:Excavations at Huacaloma and Layzón, 1982. University of Tokyo Press.

1988 Las Excavaciones en Cerro Blanco y Huacaloma, Cajamarca, Perú, 1985. Andes Chosashitsu, Departamento de Antropología Cultural, Universidad de Tokio.

TOBLER, Waldo

1993 Three presentations on geographical analysis and modeling: Non-Isotropic geographic modeling, speculations on the geometry of geography, global spatial analysis. Technical Report 93-1, National Center for Geographic Information and Analysis, University of California, Santa Barbara. Technical Report 93-1.

TOPIC, John R. y Theresa L. TOPIC

1983 «Coast-highland relations in northen Peru: Some observations on routes, networks, and scales of interaction». En: R.M. Leventhal y A.L. Kolata (eds.) Civilazation in the Ancient Americas, Essays in Honor of Gordon R. Willey, pp.237-259. University of New Mexico Press y Peabody Museum of Archaeology and Ethnology Harvard University.

TRIPCEVICH, Nicholas

2007 Quarries, Caravans, and Routes to Complexity: Prehispanic Obsidian in the South-Central Andes. Ph.D Disertation, University of California, Santa Barbara.

TROMBOLD, Charles D.

1990 «An introduction to the study of ancient New World road networks». En: C.D. Trombold (ed.) Ancinet Road Networks and Settlement Hierarchies in the New World, pp. 1-9. Cambridge University Press.

TSURUMI, Eisei

2008 «Explorations in the middle reaches of the valleys in northern Peru: Beginning the studies of interregional routes of the Formative period». America Antigua 11: 61-73. [en japonés].

UZAWA, Kazuhiro

2010 «La difusión de los camélidos domesticados en el norte del Perú durante el periodo Formativo». Boletín de Arqueología PUCP 12: 249-260.

VÁSQUEZ, Víctor y Teresa ROSALES THAM

2008 Análisis de restos de fauna, vegetales y granos de almidón del sitio Ingatambo. Trujillo: Arqueobios, Centro de Investigaciones Arqueobiológicas y Paleoecológicas Andinas.

2009 Análisis de restos de faunay vegetales del sitio Ingatambo. Trujillo: Arqueobios, Centro de Investigaciones Arqueobiológicas y Paleoecológicas Andinas. 
WATANABE, Shinya

2010 «Dos monolitos del sitio de Congona, Sierra norte del Perú». Boletín de Arqueología PUCP 12: 53-68.

WESTER, Carlos, Juan MARTÍNEZ y Arturo TANDAYPAN

2000 La Granja, Investigaciones Arqueológicas. Lambayeque: Museo Nacional Brüning, Sociedad Minera la Granja S.A., Cambior.

YAMAMOTO, Atsushi

2007 «El reconocimiento del valle de Huancabamba, Jaén, Cajamarca, Perú». Arkeos 2 (2): 1-16.

2010 «Ingatambo: Un Sitio estratégico de contacto interregional en la zona norte del Perú». Boletín de Arqueología PUCP 12: 25-52.

2012 Dinámica social en el Formativo de los Andes: Desde el punto de la vista de actividades y estrategias de sociedades del valle de Huancabamba, norte del Perú. Ph.D dissertation presentado a la Escuela de Estudios Culturales y Sociales, Universidad de Postgrado para Estudios Avanzados [en japonés].

YAMAMOTO, Atsushi y José PEÑA MARTÍNEZ

2006 Informe Preliminar del Proyecto de Investigación Arqueológica en el Valle de Huancabamba, Perú, Lima: INC.

2007 Informe del Proyecto de Investigación Arqueológica «Ingatambo», en el Valle de Huancabamba, Provincia de Jaén, Departamento de Cajamarca, Perú, Lima: INC.

2008 Informe del Proyecto de Investigación Arqueológica «Ingtambo», en el Valle de Huancabamba, Provincia de Jaén, Departamento de Cajamarca, Perú (Segunda Temporada), Lima: INC. 